\title{
German claims data analysis to assess impact of different intraocular lenses on posterior capsule opacification and related healthcare costs
}

\author{
Nils Kossack $^{1} \cdot$ Christian Schindler $^{1}$ (D) - Ines Weinhold ${ }^{1} \cdot$ Lennart Hickstein $^{2}$ • \\ Moritz Lehne $^{3} \cdot$ Jochen Walker $^{2} \cdot$ Aljoscha S. Neubauer $^{4}$ - Dennis Häckl ${ }^{1}$
}

Received: 12 May 2017 / Accepted: 26 September 2017 / Published online: 24 October 2017

(C) The Author(s) 2017. This article is an open access publication, corrected publication January/2018

\begin{abstract}
Aim Cataract extraction is one of the most frequent surgeries in Germany. In most cases, the clouded natural lens is replaced by a hydrophobic or hydrophilic acrylic intraocular lens (IOL) implant. The most common long-term complication after cataract surgery is the development of a posterior capsule opacification (PCO). Although no precise real world data are available, published evidence suggests a lower risk for PCO development for hydrophobic acrylic IOLs compared to hydrophilic acrylic IOLs. Therefore, in the present study we assessed real world data on the impact of different IOL material types on the incidence of post-operative PCO treatment. Subject and methods In this retrospective study, we included 3,025 patients who underwent cataract extraction and implantation of either an acrylic hydrophobic or hydrophilic IOL in 2010. We assessed clinical outcomes and direct costs in a 4year follow-up period after cataract surgery from a statutory health insurance (SHI) perspective in Germany.

Results PCO that required capsulotomies occurred significantly $(p<0.0001)$ less frequent in patients who had received a hydrophobic IOL (31.57\% of 2,078 patients) compared to the group with hydrophilic IOL implants $(56.6 \%$ of 947 patients) and costs per patient for postoperative treatment in a 4-
\end{abstract}

Christian Schindler

schindler@wig2.de

1 WIG2 Institute for Health Economics and Health System Research, Leipzig, Germany

2 InGef Institut für angewandte Gesundheitsforschung, Berlin, Germany

3 Elsevier Health Analytics, Berlin, Germany

4 Praxis für Augenheilkunde und Institut für Gesundheitsökonomik, Munich, Germany year follow-up were $50.03 €$ vs. $87.81 €($ i.e. $75 \%$ higher in the latter group, $p<0.0001$ ).

Conclusion Considering the high prevalence of cataract, the economic burden associated with adverse effects of cataract extraction is of great relevance for the German SHI. Hydrophobic lenses seem to be superior regarding both medical and economic results.

Keywords Cataract · Acrylic hydrophobic/hydrophilic intraocular lens · Posterior capsule opacification · Follow-up costs $\cdot$ Neodymium-doped yttrium-aluminum-garnet (Nd:YAG) laser capsulotomy

JEL classification $\mathrm{I} 10 \cdot \mathrm{I} 13$

\section{Introduction}

Cataract, the clouding or loss of transparency of the eye's natural lens is the leading cause for blindness worldwide (Abraham et al. 2006). Prevalence rates of age-related cataract as the most common form considerably increases from about $30 \%$ for the 60-69-year-old population up to more than $60 \%$ for those older than 70 years (Prokofyeva et al. 2013). Up to now, surgical cataract extraction is the sole effective treatment to restore visual function and prevent blindness (Prokofyeva et al. 2013). With about 850,000 up to $1,000,000$ yearly cases, cataract extraction is one of the most frequently performed surgeries in Germany, representing a high economic burden to the healthcare system (AQUA - Institut für angewandte Qualitätsförderung und Forschung im Gesundheitswesen GmbH 2010). During the procedure, the affected lens is extracted and replaced by an IOL implant. IOLs are available in four optic materials, i.e. polymethylmethacrylate (PMMA), high water content hydrophilic acrylic, low water content 
hydrophobic acrylic and hydrophobic silicone. Up to now, hydrophobic acrylic is the most frequently implemented IOL material (Lundström et al. 2012).

\section{Clinical and economic impact of complications after cataract surgery}

Risks of cataract surgery itself (e.g. posterior capsular rupture, zonular dehiscence or suprachoroidal hemorrhage) are generally low (AQUA - Institut für angewandte Qualitätsförderung und Forschung im Gesundheitswesen GmbH 2010; Chan et al. 2010; Lundström et al. 2012). Postsurgical complications such as changes in intraocular pressure, inflammations (i.e. uveitis, endophthalmitis) or a corneal edema occur sometimes $(<0.4 \%)$ within a short time frame after surgery (Lundström et al. 2012). Also there is a risk of $0.9 \%$ for a retinal detachment in the first 4 years (Chan et al. 2010); therefore, a treatment of glaucoma, a vitreoretinal intervention or an explantation with secondary implantation of an IOL could rarely occur. The by-farmost frequent long-term complication after cataract surgery is a PCO, which usually occurs a few weeks up to several years after cataract surgery (Findl et al. 2007). PCO results in a decreased visual acuity, impairing the patient. In addition, PCO causes impaired contrast sensitivity and glare disability (Nibourg et al. 2015). A development of PCO within a maximum of 1 year after cataract extraction is estimated at 4.2\% (Greenberg et al. 2011). Within a 2-4 years' time frame, an incidence rate of $22.8 \%$ (Auffarth et al. 2004) to $38.5 \%$ (Fong et al. 2014) has been reported in cataract patients. This so-called secondary cataract can be treated with neodymium-doped yttrium-aluminumgarnet (Nd:YAG) laser capsulotomy, which is generally safe and the standard treatment procedure up to now (Karahan et al. 2014a); however, the Nd:YAG laser treatment of PCO itself can cause secondary effects. Transient increase of an intraocular pressure is observed in $5 \%$ of all cases and a decrease in visual acuity in about $4 \%$ (Boureau et al. 2009a). Other effects (glaucoma, cystoid macular edema or detachment of the retina) appear in less than $1.5 \%$ of laser-treated patients (Karahan et al. 2014b). The main complication is the formation of Elschnig pearls, which affects about $47.60 \%$ of the treated patients (Boureau et al. 2009a). On average, a secondary capsulotomy is necessary for every fourth patient (Kato et al. 1997).

Postsurgical complications cause a considerably part of the total costs of cataract treatment (Smith et al. 2005; Boureau et al. 2009a). In the US health system Nd:YAG laser capsulotomy accounts for $\$ 500,000,000$ annually and is ranked second place in cost statistics for health interventions following cataract surgery itself (Menapace 2007). Billotte and Berdeaux (2004) estimated that in the long-term, ${ }^{1}$ up to 11,500 adverse events based on 400,000 cataract extractions

\footnotetext{
${ }^{1}$ Up to 9 years after surgery
}

could be avoided if Nd:YAG laser capsulotomy rates could be reduced. To develop effective strategies for PCO prevention, several influencing factors such as material and design of the implanted lens, surgical technique (Pandey et al. 2004), as well as pharmacological management during and post operation are discussed in the literature (Dewey 2006; Wormstone et al. 2009; Chandler et al. 2015; Nibourg et al. 2015). Comparing the available types of IOL materials, PCO development seems to be less likely after hydrophobic acrylic lense implantation compared to hydrophilic acrylic or silicone lens implants (Auffarth et al. 2004; Vasavada et al. 2011; Li et al. 2013; Sundelin et al. 2014). A further factor for the development of PCO seems to be the design of the lens, in favor of sharp-edged compared to round-edged IOLs (Findl et al. 2007; Mencucci et al. 2015).

The present analysis builds on the results of a preliminary study (Kossack et al. 2016). It assesses the impact of two different IOL material types (hydrophobic and hydrophilic acrylate) on the development of PCO rates and other complications related to cataract surgery combined with the associated costs in a 4-year follow-up based on a random sampling from SHI claims data. We performed a retrospective analysis to compare:

1. The incidence of PCO and Nd:YAG laser capsulotomy after cataract extraction in relation to hydrophobic and hydrophilic acrylic IOL implantation in current German practice

2. The associated costs of Nd:YAG laser capsulotomy due to PCO after cataract extraction from a SHI perspective

\section{Study design/material and methods}

\section{Data and study population}

Anonymized claims data were provided by the Institut für angewandte Gesundheitsforschung (InGef). The InGef research database covers approximately 6.7 million insured persons from different German SHIs, mainly company health insurance funds. The external validity of this database compared to German population data has been shown previously (Andersohn and Walker 2016). For the present study, a sample of approximately 4 million insured persons served as study population. This sample is representative for the German population with regard to age and sex for the year 2013. The database includes demographic information, diagnoses, utilization of ambulatory services, hospitalizations and reimbursed drugs as well as remedies and aids on a patient individual level. In Germany, SHI reimbursement of ambulatory services is regulated by the German National Ambulatory Evaluation Scheme (EBM). Utilization of outpatient services can thus be 
identified by the invoiced fee schedule position numbers (GOP). For historic reasons only, in the region of Bavaria these position numbers differ for the type of implanted IOL, enabling us to differentiate between an implantation of hydrophobic (GOP: 96104A) and hydrophilic (GOP: 96104B) acrylic IOLs. All patient-level data in the InGef database is de-identified to comply with German data protection regulations and German Federal Law; hence, approval of an institutional review board or ethics committee was not required.

The two groups under comparison were selected by a stepwise approach. First, we identified individuals who had been living in Bavaria without interruption and were continuously SHI insured within our study period 2009-2014. Relevant patients were identified with a diagnosis code of cataract according to the International Classification of Diseases, Tenth Revision (ICD-10) codes (cataracta senilis: H25, other cataract: H26, diabetic cataract/cataract in other endocrine, nutritional and metabolic diseases/cataract in other diseases classified elsewhere: H28, without other disorders of lens in diseases classified elsewhere: H28.8) and a surgical cataract extraction with an acrylic IOL implant in 2010 (index period). Patients who received both types of acrylic implants as well as patients who already have had an IOL implant before 2010 were excluded from the analysis. In a second step, we divided this sample into two subsamples depending on whether a hydrophobic or hydrophilic acrylic IOL had been implanted after cataract extraction.

\section{Group comparison}

By comparing the two study groups, we analyzed the impact of the implanted IOL material (hydrophobic acrylic versus hydrophilic acrylic) on the development of PCO rates in a 4year follow-up. The incidence of PCO was identified in patients who underwent capsulotomy, which was identified by documented ICPM (International Classification of Procedures in Medicine) codes for the procedures of laser capsule polishing (5-142.0), surgical capsulotomy (5-142.1), Nd:YAG laser capsulotomy (5-142.2) or surgical posterior capsule polishing (5-142.3). To eliminate potential confounders, we additionally considered the following postoperative adverse effects as control variables: changes of intraocular pressure by treatment of glaucoma (procedure codes: 5$131,5-132,5-133,5-134)$, a retinal detachment by vitreoretinal intervention (procedure codes: 5-158, 5-159) and an explantation of the newly implanted IOL with implantation of a next IOL - explantation with secondary implantation of an IOL (procedure codes: 5-146, 5-147.2, 5-147.3).

In order to ensure comparability of the study populations we analyzed sociodemographic structures as well as their respective medical history within 12 months prior to the cataract extraction. We considered the most relevant comorbidities as well as relevant drugs with a potential impact on PCO development/postoperative complications. Relevant comorbidities include retinal detachment and tear (H33), glaucoma (H40), diabetes mellitus (E10-E14) and hypertension (I10 I15; Pham et al. 2004). Certain medical treatments, systemic as well as topical, can have an influence on the proliferation of cells (Guo and DiPietro 2010; Noon et al. 2013), i.e., pharmacological interventions during or after surgery with the goal of depleting or inhibiting regeneration of remaining lens epithelial cells. Systemic drugs with a potential impact on complications such as cytostatic drugs, immunosuppressant drugs like corticosteroids and selective serotonin reuptake inhibitors (SSRI), a group of drugs which is mainly prescribed in case of depression, were identified by assessing the prescriptions based on ATC codes for pharmaceutical treatment, i.e., cytostatic drugs (ATC L01 and PZN 9999092, 2566881), Cortisone (ATC: H02, S01BA, S01BB, S01BX, S01CA, S01CB) and SSRI (ATC: N06AB02-10). To control for the severity of a patient's comorbidities, we considered the Charlson comorbidity index (Charlson et al. 1987), which predicts the 1-year mortality.

We used Fisher's exact test and Welch's t-test to identify significant group differences and Bonferroni correction to avoid a false rejection of the null-hypothesis due to multiple testing in the same sample. ${ }^{2}$ To assess the impact of the risk factors on the dependent variable PCO incidence we used a weighted multivariate logistic regression. We included age at cataract surgery, gender, the implanted IOL type and comorbidities as well as prescribed medication. Patients with a contralateral IOL implantation during the follow-up period got a higher weight in the regression analysis to counterbalance the higher risk of PCO caused by the second IOL-implantation. All analyses were performed in SAS version 9.2 using a proc. logistic model with effect coding. Statistical significance was set at $p<0.05$.

\section{Costs of complications}

The economic analysis compared direct costs over a period of 48 months after cataract surgery from an SHI payer perspective. Follow-up capsulotomy after IOL implantation is usually performed in outpatient settings in Germany. To calculate costs, we thus valued these interventions by means of the EBM of 2014. The number of follow-up Nd:YAG laser capsulotomies was calculated by summing up the respective invoiced EBM codes $31341^{3}$ per patient in each group when the relevant procedures were coded. We additionally identified all billing positions that are related to PCO treatment. These include postoperative monitoring (EBM code 31501)

\footnotetext{
${ }^{2}$ The Bonferroni correction is based on the idea that local significance levels for each of the independent hypothesis tests can be divided by the total number of hypotheses in order to test a global significance level.

${ }^{3}$ laser-surgical intervention of category W1
} 
Table 1 Selection of insured persons

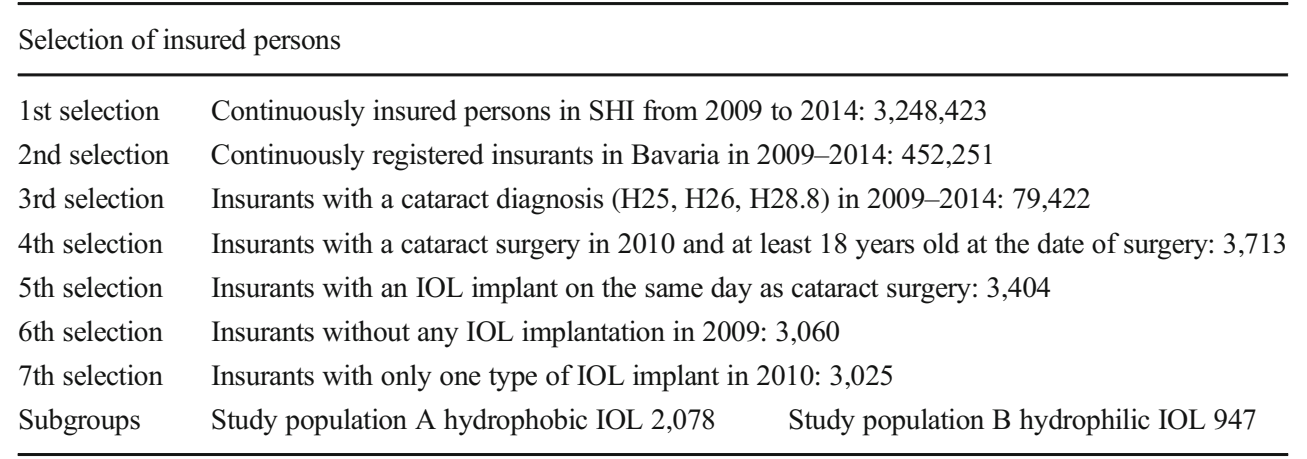

and postoperative services either based on the surgeon's referral (EBM code 31724) or performed by the operating surgeon $\mathrm{him} /$ herself (EBM code 31725). Since we used the most recent available version of the scheme, we did not discount costs in the analysis.

\section{Results}

\section{Study population and subgroup comparison}

A total of 3,025 patient records with acrylic IOL implants was selected from the database as described in the methods section (Table 1). The records were grouped by the type of IOL material. From the total population, 2,078 patients obtained a hydrophobic IOL (study population A: hydrophobic IOL) and 947 patients got a hydrophilic implant (study population B: hydrophilic IOL).

The mean age of the study population $\mathrm{A}$ is slightly higher compared to group $\mathrm{B}$ and both populations were predominately females (A: 59.34\%; B: 57.34\%; Table 2). Age and gender distributions of the subgroups are shown in Table 3 . In this cohort, cataract diagnosis was more prevalent in older patients. The highest rates were found in the 66-85-year-old age groups.

The most relevant comorbidities for an IOL implantation and the Charlson comorbidity index were analyzed for a period of 12 months before the surgery (Table 4). A large proportion of patients suffered from hypertension $(>70 \%)$ or diabetes $(\sim 30 \%)$. Glaucoma was diagnosed in around $18 \%$ of all cases in each group, whereas a retinal detachment and a retinal tear appeared less frequently $(<2 \%)$. The prevalence rates for diabetes and hypertension were as expected, given the high mean age of both populations. It is known, that older patients suffering from diabetes may have an increased risk of postoperative complications and decreased postoperative visual functions (Lara-Smalling and Cakiner-Egilmez 2014) as well as for the development of PCO in the short-term (Hayashi et al. 2002; Ebihara et al. 2006; Raj et al. 2007); nevertheless, recent studies (Nekolová et al. 2008; Praveen et al. 2014) show, that diabetes mellitus does not increase the incidence of PCO in the long term, i.e. after 4 , respectively 7 , years. As this study is based on ICD diagnosis coding, there is no information available on severity of diabetes or diabetic symptoms, but also Hayashi et al. (2002) and Praveen et al. (2014) found that the diabetic severity has no influence on the development of PCO. Although the percentage of diabetic patients is higher in population $\mathrm{B}$, diabetes is seen as a confounder without relation to $\mathrm{PCO}$ incidence. The mean score of the Charlson comorbidity index is 2.00 for study population A and 2.03 for study population $\mathrm{B}$.

Table 5 depicts the rates of patients with prescriptions of drugs that potentially influence PCO incidence and surgery outcomes. About half of the patients received cortisone (topical medication) in the year before the surgery. About 4-5\% of patients also received SSRI, whereas cytostatic drugs rarely appear. Using Fisher's exact test and Bonferroni correction to adjust for multiple testing, we found no between-group differences in the preoperative characteristics at a 5\% global significance level, so comparability of the populations could be assumed.

\section{Complications after cataract surgery}

Since PCO is the most frequent complication after IOL implantation, its incidence rate is a valid indicator of treatment quality. As shown in Table 6, PCO is treated in more than $99 \%$ of all cases by $\mathrm{Nd}$ :YAG laser capsulotomy; thus, in line with
Table 2 Socio-demographic variables of the study populations

\begin{tabular}{llll}
\hline & Study population A hydrophobic IOL & Study population B hydrophilic IOL & $p$ value $^{\text {a }}$ \\
\hline Female & $59.34 \%$ & $57.34 \%$ & 0.3009 \\
Mean age (SD) & $72.79(8.41)$ & $73.64(8.44)$ & 0.0099 \\
\hline
\end{tabular}

${ }^{a}$ Gender: Fisher's exact test; age: Welch's test; local significance level $\alpha=0.005$ after Bonferroni correction 
Table 3 Age and gender distributions

\begin{tabular}{|c|c|c|c|c|c|c|c|c|}
\hline \multirow[t]{2}{*}{ Age group } & \multicolumn{4}{|c|}{ Study population A hydrophobic IOL } & \multicolumn{4}{|c|}{ Study population B hydrophilic IOL } \\
\hline & Male & Female & Total & Percentage & Male & Female & Total & Percentage \\
\hline $18-50$ & 17 & 18 & 35 & $1.68 \%$ & 12 & 11 & 23 & $2.43 \%$ \\
\hline $51-55$ & 19 & 24 & 43 & $2.07 \%$ & 8 & 5 & 13 & $1.37 \%$ \\
\hline $56-60$ & 40 & 50 & 90 & $4.33 \%$ & 26 & 8 & 34 & $3.59 \%$ \\
\hline $61-65$ & 79 & 90 & 169 & $8.13 \%$ & 31 & 26 & 57 & $6.02 \%$ \\
\hline $66-70$ & 151 & 217 & 368 & $17.71 \%$ & 60 & 79 & 139 & $14.68 \%$ \\
\hline $71-75$ & 245 & 318 & 563 & $27.09 \%$ & 108 & 163 & 271 & $28.62 \%$ \\
\hline $76-80$ & 175 & 267 & 442 & $21.27 \%$ & 95 & 131 & 226 & $23.86 \%$ \\
\hline $81-85$ & 92 & 194 & 286 & $13.76 \%$ & 50 & 86 & 136 & $14.36 \%$ \\
\hline $86-90$ & 27 & 49 & 76 & $3.66 \%$ & 13 & 30 & 43 & $4.54 \%$ \\
\hline $91-120$ & 0 & 6 & 6 & $0.29 \%$ & 1 & 4 & 5 & $0.53 \%$ \\
\hline Total & 845 & 1,233 & 2,078 & $100.00 \%$ & 404 & 543 & 947 & $100.00 \%$ \\
\hline
\end{tabular}

the literature (Findl et al. 2007), PCO treatment can be sufficiently referred to as $\mathrm{Nd}$ :YAG laser capsulotomy.

Within 4 years after IOL implantation, the frequency of PCO treatment was significantly lower in the group of patients with a hydrophobic IOL implant $\left(n_{\text {abs }}=656 ; 31.57 \%\right)$ compared with patients in study population $\mathrm{B}\left(n_{\mathrm{abs}}=536 ; 56.60 \%\right.$; $p<0.0001)$. Figure 1 presents the proportions of the patients who underwent PCO treatment by Nd:YAG laser capsulotomy or surgical intervention within 4 years after the implantation of the IOL. The curves confirm that PCO treatment occurred more frequently in the hydrophilic IOL group in every quarter after cataract surgery.

To exclude potential confounders, other adverse effects that required follow-up surgery are taken into account as control variables as shown in Table 7 . There was no statistically significant difference between the groups, so that PCO could be considered as the single indicator for the treatment quality outcome.

The regression results and odds ratios in Table 8 show that the type of IOL implant exerts the strongest negative impact
Table 4 Morbidity structure of the study populations

Table 5 Medication of the study populations

\begin{tabular}{|c|c|c|c|c|c|}
\hline \multirow[t]{2}{*}{ Comorbidity } & \multicolumn{2}{|c|}{$\begin{array}{l}\text { Study population A hydrophobic } \\
\text { IOL }\end{array}$} & \multicolumn{2}{|c|}{$\begin{array}{l}\text { Study population B hydrophilic } \\
\text { IOL }\end{array}$} & \multirow[t]{2}{*}{$p$ value } \\
\hline & Total & Percentage & Total & Percentage & \\
\hline Retinal detachment and tear & 41 & $1.97 \%$ & 17 & $1.80 \%$ & 0.8864 \\
\hline Glaucoma & 376 & $18.09 \%$ & 183 & $19.32 \%$ & 0.4194 \\
\hline Diabetes mellitus & 615 & $29.60 \%$ & 305 & $32.21 \%$ & 0.1477 \\
\hline Hypertension & 1,536 & $73.92 \%$ & 701 & $74.02 \%$ & 0.9644 \\
\hline Charlson index, mean (SD) & $2.00(1.96)$ & & $2.03(1.99)$ & & 0.6947 \\
\hline
\end{tabular}

${ }^{a}$ Comorbidity: Fisher's exact test; Charlson index: Welch's test; local significance level $\alpha=0.005$ after Bonferroni correction

\begin{tabular}{|c|c|c|c|c|c|}
\hline \multirow[t]{2}{*}{ Medication } & \multicolumn{2}{|c|}{ Study population A hydrophobic IOL } & \multicolumn{2}{|c|}{ Study population B hydrophilic IOL } & \multirow[t]{2}{*}{$p$ value $^{\mathrm{a}}$} \\
\hline & Total & Percentage & Total & Percentage & \\
\hline Cytostatic & 21 & $1.01 \%$ & 6 & $0.63 \%$ & 0.4054 \\
\hline SSRI & 109 & $5.25 \%$ & 38 & $4.01 \%$ & 0.1711 \\
\hline Cortisone & 1129 & $54.33 \%$ & 471 & $49.74 \%$ & 0.0205 \\
\hline
\end{tabular}

${ }^{\text {a }}$ Fisher's exact test; local significance level $\alpha=0.005$ after Bonferroni correction 
Table 6 Types of PCO treatment

\begin{tabular}{lccccc}
\hline & \multicolumn{2}{c}{ Study population A hydrophobic IOL } & & \multicolumn{2}{c}{ Study population B hydrophilic IOL } \\
\cline { 2 - 3 } & Total & Percentage & & Total & Percentage \\
\hline PCO treatment overall & 656 & & 536 & \\
Nd:YAG laser capsulotomy & 651 & $99.24 \%$ & & 532 & $99.25 \%$ \\
Surgical intervention & 5 & $0.76 \%$ & & 4 & $0.75 \%$ \\
\hline
\end{tabular}

on expected PCO incidence rates $(-0.5143, p<0.0001)$. For patients with hydrophobic IOL implants, the likelihood is reduced by a factor of 0.3575 . Sex, i.e. male $(-0.1775$, $p<0.0001$, OR 0.7012) and a diagnosed hypertension $(-0.0915, p<0.05$, OR 0.8328$)$ are moderately related to a lower PCO development. Glaucoma $(0.0833, p<0.05)$ as well as a prescription of cytostatic drugs $(0.3972, p<0.05)$ are related to an increased likelihood of PCO. Age, diabetes, retinal detachment and tear, as well as the prescription of cortisone and SSRI are not significantly related to PCO incidence.

\section{Economic impact}

Due to the higher PCO incidence in hydrophilic group, $\mathrm{Nd}$ :YAG laser capsulotomy after cataract surgery was subsequently more often performed in this group as well. In fact, 0.51 fee schedule positions per patient were billed for the hydrophobic group and 0.9 per patient for the hydrophilic group (Table 9). Associated treatments are likewise more frequent in the hydrophilic study population B. 0.46 positions per patient accounted for postsurgical monitoring in the hydrophobic, compared to 0.82 positions in the hydrophilic group. Furthermore, a considerably higher sum of billed positions per patient was scheduled for postoperative treatments conducted by the surgeon in the hydrophilic group ( 0.37 vs. 0.66). The average costs per patient (i.e. not per treatment) were $50.03 €$ for the hydrophobic group and $87.81 €$ for the hydrophilic group.

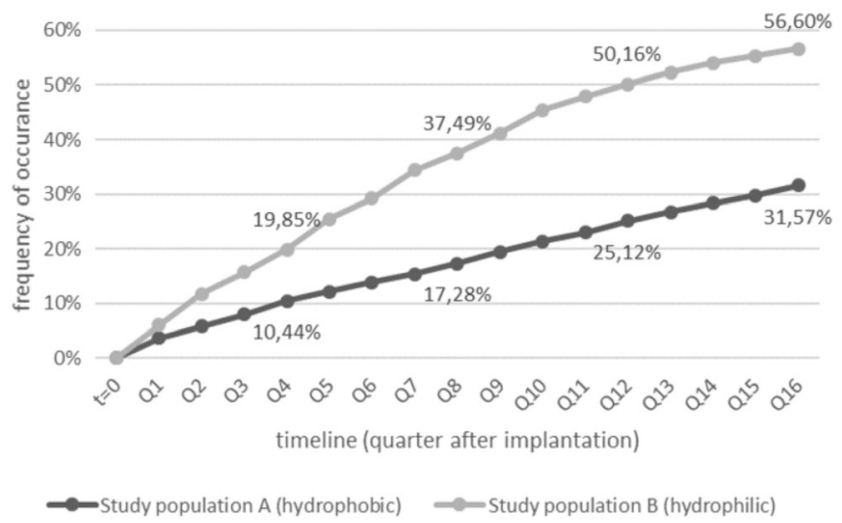

Fig. 1 Patients with treatment of PCO (Nd:YAG laser capsulotomy or surgical intervention)
The average postoperative costs due to PCO treatment by Nd:YAG laser capsulotomy for patients with hydrophilic IOL are about $75 \%$ higher compared to patients with hydrophobic IOL implants. Within the scope of this cost analysis the base flat rate for ophthalmologists ${ }^{4}$ is not considered because it is not clearly attributable to the PCO treatment. Assuming that these contacts are also related to PCO treatment, the economical advantageousness of the hydrophobic lens would increase even more.

Occasionally, there is a need for another IOL implantation in the contralateral eye. Such an additional intervention has to be considered in the economic impact assessment. Since the ratio of cataract patients that underwent a contralateral IOL implantation in the follow-up period differs between the groups (Table 10), the associated PCO risk and the necessity of its treatment differ as well.

If the follow-up time of the contralateral IOL implantation is measured too, this results in an average 1.57-year follow-up of the contralateral eye in population A and 1.53-year in population $\mathrm{B}(p=0.1222)$. Considering both eyes, this yields a summarized average follow-up time of 5.57 years (population A) and 5.53 years (population B), respectively. Since a contralateral IOL-implantation increases the risk for a PCO treatment, the average costs for patients with hydrophobic IOL implants are overestimated by around $2.6 \%{ }^{5}$ and therefore should be decreased by this factor compared to hydrophilic IOL. ${ }^{6}$ This would result in average costs of $48.72 €$ for population A.

\section{Discussion}

This retrospective analysis was performed to compare the incidence of PCO measured by Nd:YAG laser capsulotomy or surgical intervention after implantation of either hydrophobic or hydrophilic IOLs following cataract extraction. Additionally, other postoperative adverse events such as glaucoma, vitreoretinal interventions and the explantation and replacement of the IOL were considered as control variables. The focus of

\footnotetext{
$\left.\overline{{ }^{4} \text { EBM 06210, } 06211,06212 ~(12.87 € ~ t o ~} 15.60 €\right)$

${ }^{5}$ Due to the $2.6 \%$ longer follow-up time of the contralateral IOL implantation for population A (1.57 year vs. 1.53 year)

${ }^{6}$ Assuming the costs increase in an equal proportion
} 
Table 7 Postoperative

complications (control variables)

\begin{tabular}{lllllll}
\hline & $\begin{array}{l}\text { Study population A } \\
\text { hydrophobic IOL }\end{array}$ & & $\begin{array}{l}\text { Study population B } \\
\text { hydrophilic IOL }\end{array}$ & $p$ value $^{\mathrm{a}}$ \\
\cline { 2 - 3 } & Total & Percentage & Total & Percentage & \\
\hline Glaucoma & 71 & $3.42 \%$ & & 24 & $2.53 \%$ & 0.2172 \\
Vitreoretinal intervention & 56 & $2.69 \%$ & & 20 & $2.11 \%$ & 0.3821 \\
Explantation and secondary implantation of an IOL & 57 & $2.74 \%$ & & 24 & $2.53 \%$ & 0.8087 \\
\hline
\end{tabular}

${ }^{a}$ Fisher's exact test

the economic analysis was to assess the follow-up costs related to the different implanted IOL materials and the potentially following complications from an SHI perspective.

Most of the available evidence to compare IOL-types is provided by retrospective cohort studies or randomized controlled trials (RCT) with small sample sizes under artificial controlled study conditions mainly with short follow-up times. Under these conditions, hydrophobic acrylic lens material (compared to hydrophilic IOLs) was found to be related to a lower risk of PCO development measured by the rate of $\mathrm{Nd}$ :YAG laser capsulotomy compared to hydrophilic acrylic IOL material ( $34 \%$ vs. $49 \%, p=0.04$; Schriefl et al. 2015).

The meta-analysis of $\mathrm{Li}$ et al. (2013) finds a relative risk of 6.96 for Nd:YAG laser capsulotomy 2 years after cataract surgery, when hydrophilic IOLs are compared with hydrophobic IOLs. Several retrospective studies come to similar conclusions. Gauthier, Lafuma, Laurendeau and Berdeaux (2010) found that the rate of Nd:YAG laser capsulotomy after bilateral hydrophobic IOL implantation was $8.8 \%$, whereas it reached $37.5 \%$ after bilateral hydrophilic IOL implantation in a 2-year follow-up of 312 eyes. Boureau et al. (2009b) found, that $45.4 \%$ of patients with hydrophilic implants had undergone Nd:YAG laser capsulotomy, while the amount was

Table 8 Results of the regression analysis (weighted logistic regression)

\begin{tabular}{lcc}
\hline Variables & Coefficient & Odds ratio \\
\hline Lens type & $-0.5143^{* * *}$ & 0.3575 \\
Socio-demographics & & \\
$\quad$ Age & -0.0031 & 0.9969 \\
$\quad$ Gender (male) & $-0.1775^{* * *}$ & 0.7012 \\
Comorbidities & & \\
Glaucoma & $0.0833^{*}$ & 1.1813 \\
Diabetes & 0.0016 & 1.0031 \\
Hypertension & $-0.0915^{*}$ & 0.8328 \\
$\quad$ Retinal detachment and tear & 0.0198 & 1.0404 \\
Medication & & \\
Cytostatic & $0.3972^{*}$ & 2.2131 \\
SSRI & -0.1182 & 0.7895 \\
Cortisone & 0.0356 & 1.0738 \\
\hline
\end{tabular}

$* \mathrm{p}<0.05 ; * * \mathrm{p}<0.001 ; * * * \mathrm{p}<0.0001$ significantly lower $(p<0.001)$ if a hydrophobic IOL was implanted (13\%/23.4\%). However, the summarized cohort or RCT to compare rates of Nd:YAG laser capsulotomy in relation to different IOL had small sample sizes (675 patients on the average) and follow-up periods of 1-3 years after the first IOL implantation (Auffarth et al. 2004; Boureau et al. 2009b; Gauthier et al. 2010; Vasavada et al. 2011; Li et al. 2013). Many scientific conclusions were made accordingly (e.g. as Auffarth et al. (2004) that state, incidence rates of $\mathrm{Nd}$ :YAG laser capsulotomy do not considerably decrease over a 3-year follow up period).

In contrast, the present study assessed a population of 3,025 patients in a 4-year-follow-up under real world conditions. Accordingly, our results add to the scientific knowledge of Nd:YAG laser capsulotomies within longer time frames and with a large study population under real world conditions.

A considerable part of cataract-associated costs results from complications of the surgery and its treatments as well as related secondary adverse events; however, economic analysis from a SHI perspective has been very limited up to now. Based on a retrospective, multicenter study including 767 eyes treated, Boureau et al. (2009a, b) calculated a model of patients' lifetime costs from a French SHI perspective for populations that either had hydrophobic or hydrophilic acrylic IOL implanted. Direct and indirect cost estimates were derived from official French documents, published literature and expert declarations. The authors found significantly higher adjusted risk ratios of undergoing an Nd:YAG laser capsulotomy (RR: $5.1 ; p<0.0001$ ) for hydrophilic lenses compared to the hydrophobic IOL. For a linear extrapolation of Nd:YAG laser capsulotomy rates from 5 to 26 years of follow-up, total costs of treatment and management of complications per patient ${ }^{7}$ were more than 3-times higher for patients with a hydrophilic lens implant $(268.90 €)$ compared to the best performing hydrophobic implant $(84.78 €)$ in the study. Indirect costs, associated to the risk of blindness, account for a considerable amount of about $42 \%$ of total costs. In the budget analyses, savings of $21.936 .621 €$ from a French SHI perspective were estimated if all patients undergoing cataract extraction in 2005 switched to the better-performing IOL material (Boureau et al. 2009a). Due to the differences in

\footnotetext{
${ }^{7} 5 \%$ discount rate
} 
Table 9 Mean costs of PCO treatment by $\mathrm{Nd}$ :YAG laser capsulotomy

\begin{tabular}{|c|c|c|c|c|c|}
\hline & \multirow[t]{2}{*}{ Type of treatment } & \multicolumn{2}{|c|}{$\begin{array}{l}\text { Study population A } \\
\text { hydrophobic IOL }\end{array}$} & \multicolumn{2}{|c|}{$\begin{array}{l}\text { Study population B } \\
\text { hydrophilic IOL }\end{array}$} \\
\hline & & Sum & $\begin{array}{l}\text { Per } \\
\text { patient }\end{array}$ & Sum & $\begin{array}{l}\text { Per } \\
\text { patient }\end{array}$ \\
\hline Total number of patients & & 2078 & & 947 & \\
\hline \multirow[t]{4}{*}{$\begin{array}{l}\text { Number of billed fee } \\
\text { schedule positions }\end{array}$} & $\begin{array}{l}\text { Laser-surgical intervention } \\
\text { of category W1 }\end{array}$ & 1058 & 0.51 & 849 & 0.90 \\
\hline & Postsurgical monitoring & 961 & 0.46 & 773 & 0.82 \\
\hline & $\begin{array}{l}\text { Postoperative treatment } \\
\quad \text { (referral) }\end{array}$ & 83 & 0.04 & 41 & 0.04 \\
\hline & $\begin{array}{l}\text { Postoperative treatment } \\
\quad \text { (surgeon) }\end{array}$ & 773 & 0.37 & 628 & 0.66 \\
\hline \multirow[t]{4}{*}{$\begin{array}{l}\text { Cumulative costs per } \\
\text { treatment }\end{array}$} & $\begin{array}{l}\text { Laser-surgical intervention } \\
\text { of category W1 (78.68 } € \\
\text { per fee schedule } \\
\text { position })^{\mathrm{a}}\end{array}$ & $83,243.44 €$ & $40.06 €$ & $66,799.32 €$ & $70.54 €$ \\
\hline & 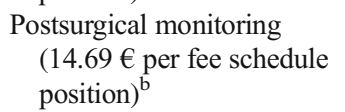 & $14,117.09 €$ & $6.79 €$ & $11,355.37 €$ & $11.99 €$ \\
\hline & $\begin{array}{l}\text { Postoperative treatment } \\
\text { (referral) }(13.46 € \text { per fee } \\
\text { schedule position })^{\mathrm{c}}\end{array}$ & $1117.18 €$ & $0.54 €$ & $551.86 €$ & $0.58 €$ \\
\hline & 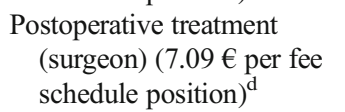 & $5480.57 €$ & $2.64 €$ & $4452.52 €$ & $4.70 €$ \\
\hline Costs PCO treatment & & $103,958.28 €$ & $50.03 €$ & $83,159.07 €$ & $87.81 €$ \\
\hline \multicolumn{6}{|l|}{${ }^{\mathrm{a}}$ EBM 31341} \\
\hline \multicolumn{6}{|l|}{${ }^{\mathrm{b}} \mathrm{BM} 31501$} \\
\hline \multicolumn{6}{|l|}{${ }^{\mathrm{c}}$ EBM 31724} \\
\hline${ }^{d}$ EBM 31725 & & & & & \\
\hline
\end{tabular}

national economic regulation, a generalizability of the results is however limited; moreover, the modeling approach is susceptible to uncertainties with regard to variable quality of the information considered. Complication rates have not been collected from medical records or claims data but estimated based on the literature, which might cause some imprecision. Smith et al. (2005) compared cost-effectiveness ratios, i.e. costs per patient successfully treated without $\mathrm{Nd}$ :YAG laser capsulotomy, of four types of IOL material in a retrospective cross-country study. Their results show that hydrophobic IOLs seem to be more cost-effective than other materials in most countries. Costs were estimated on the basis on official documents and the mean total costs per successfully treated patient and IOL-type were computed and compared. However, the differences in regulatory frameworks and reimbursements between countries influence the economic estimates and limit the comparability of the results.

Comparing the follow-up costs associated with PCO treatment by Nd:YAG laser capsulotomy and post-operative monitoring and services, our results point in the same direction as previous studies (Smith et al. 2005; Boureau et al. 2009a). The difference in average costs per patient indicates the superiority of hydrophobic lens material from an economic point of view.
Our results add to the scarce health economic evidence related to treatment of complications after cataract surgery regarding two main aspects. Firstly, in contrast to available research (Smith et al. 2005; Boureau et al. 2009a) our health economic analysis is based on longitudinal claims data. To our knowledge, there is no study that compares different IOL material types combined with a cost analysis based on real world claims data. Results from real world economic analysis is particularly important for payers (i.e. statutory health insurance in Germany) to make value-basedcoverage and re-imbursementdecisions (Garrison et al. 2007). The database we used is characterized by a good accordance with the German population regarding sociodemographic indicators, morbidity, mortality and medication use. Thus, generalizability of the results is superior compared to studies including records from selected health care providers. Persistence with the database is high $(78.5 \%$ of the insurants can be observed from 2009 to 2013); hence, longitudinal analysis is very reliable (Andersohn and Walker 2016). In contrast to retrospective multicenter post-test studies that account for most of the outlined evidence of IOL-related outcomes research, SHI claims data reflect daily practice and cover the whole spectrum of treatments and prescriptions by different health care providers (Pigeot et al. 2008). It guarantees $100 \%$ 
Table 10 Contralateral IOLimplantation in the follow-up period

\begin{tabular}{llll}
\hline $\begin{array}{l}\text { Contralateral IOL- } \\
\text { implantation }\end{array}$ & $\begin{array}{l}\text { Study population A hydrophobic } \\
\text { IOL }\end{array}$ & $\begin{array}{l}\text { Study population B hydrophilic } \\
\text { IOL }\end{array}$ & $\begin{array}{l}p \\
\text { value }^{\mathrm{a}}\end{array}$ \\
\hline In 1-year follow-up & $56.59 \%$ & $50.69 \%$ & 0.0028 \\
In 2-year follow-up & $60.30 \%$ & $55.23 \%$ & 0.0096 \\
In 3-year follow-up & $61.93 \%$ & $58.82 \%$ & 0.1080 \\
In 4-year follow-up & $64.29 \%$ & $61.35 \%$ & 0.1222 \\
\hline
\end{tabular}

${ }^{a}$ Fisher's exact test study participation proportions, which reduces potential selection biases; thus, it is possible to derive reliable actual SHI cost estimates.

This study has some limitations that are related to the structure and characteristics of claims data. Claims data are collected for billing purposes and occasionally there are inconsistencies and implausible values (Pigeot et al. 2008). The choice of potential confounders is limited to the available variables and a prospective design is not possible (Pigeot et al. 2008). Moreover, problems regarding the validity of diagnoses and procedure codes as well as coding errors are well-known problems in terms of billing data (Swart 2014). A differentiated coding for hydrophobic and hydrophilic acrylic IOL implantation is to our knowledge limited in Germany to the federal state of Bavaria, which may limit the generalizability of our results. However, the German SHI benefits for cataract surgery, pre-and post-operative care including treatment of complications are comparable to other federal states and related to the national reimbursement catalog for public medical services (EBM catalog). In addition, no restrictions exist regarding which IOL material should be implanted. In all German federal states, cataract surgeons can select the IOL material they prefer and coverage is granted by public reimbursement; therefore, there is no reason to assume that treatment and associated effects vary considerably in other federal states.

\section{Conclusion}

Cataract extraction as one of the most common surgical interventions in the developed world is an established and safe surgical procedure. The benefit of IOL implantation has been proven for decades; nevertheless, considering the high prevalence of cataract, the economic burden associated with treatment of long-term postoperative complications after cataract surgery is of great relevance for health budgets, also for the German SHI. This study identified different long-term outcomes under real world conditions highly related to the IOL material used. Hydrophobic acrylic lenses seem to be superior with regard to both medical and economic results compared to hydrophilic acrylic IOLs. Considering the necessity of follow-up treatments and intangible costs, the hydrophobic lens implant is likely to be preferable also from the patient's perspective. More research on patient-reported outcomes is necessary to confirm this hypothesis.

\section{Compliance with ethical standards}

Conflict of interest The authors' institutions have received payments for the development of the study design and data analysis from Alcon, a company of the Novartis Group.

Open Access This article is distributed under the terms of the Creative Commons Attribution 4.0 International License (http:// creativecommons.org/licenses/by/4.0/), which permits unrestricted use, distribution, and reproduction in any medium, provided you give appropriate credit to the original author(s) and the source, provide a link to the Creative Commons license, and indicate if changes were made.

\section{References}

Abraham AG, Condon NG, West Gower E (2006) The new epidemiology of cataract. Ophthalmol Clin N Am 19:415-425. https://doi.org/10. 1016/j.ohc.2006.07.008

Andersohn F, Walker J (2016) Characteristics and external validity of the German Health Risk Institute (HRI) Database. Pharmacoepidemiol Drug Saf 25:106-9. doi: https://doi.org/10.1002/pds.3895

AQUA - Institut für angewandte Qualitätsförderung und Forschung im Gesundheitswesen (2010) Kataraktoperation. Abschlussbericht, AQUA, Göttingen, Germany

Auffarth GU, Brezin A, Caporossi A, Lafuma A, Mendicute J, Berdeaux G, Smith AF (2004) Comparison of Nd:YAG capsulotomy rates following phacoemulsification with implantation of PMMA, silicone, or acrylic intra-ocular lenses in four European countries. Ophthalmic Epidemiol 11:319-329. https://doi.org/10.1080/ 09286580490515116

Billotte C, Berdeaux G (2004) Adverse clinical consequences of neodymium: YAG laser treatment of posterior capsule opacification. J Cataract Refract Surg 30:2064-2071. https://doi.org/10.1016/j.jcrs.2004.05.003

Boureau C, Lafuma A, Jeanbat V, Berdeaux G, Smith AF (2009a) Incidence of Nd:YAG laser capsulotomies after cataract surgery: comparison of 3 square-edged lenses of different composition. Can J Ophthalmol 44:165-170. https://doi.org/10.3129/i09-007

Boureau C, Lafuma A, Jeanbat V, Smith AF, Berdeaux G (2009b) Cost of cataract surgery after implantation of three intraocular lenses. Clin Ophthalmol 3:277-285

Chan E, Mahroo OAR, Spalton DJ (2010) Complications of cataract surgery. Clin Exp Optom 93:379-389. https://doi.org/10.1111/j. 1444-0938.2010.00516.x

Chandler HL, Gervais KJ, Lutz EA, Curto EM, Matusow RB, Wilkie DA, Gemensky-Metzler AJ (2015) Cyclosporine A prevents ex vivo 
PCO formation through induction of autophagy-mediated cell death. Exp Eye Res 134:63-72. https://doi.org/10.1016/j.exer.2015.03.020

Charlson ME, Pompei P, Ales KL, MacKenzie CR (1987) A new method of classifying prognostic comorbidity in longitudinal studies: development and validation. J Chronic Dis 40:373-383. https://doi.org/ 10.1016/0021-9681(87)90171-8

Dewey S (2006) Posterior capsule opacification. Curr Opin Ophthalmol 17:45-53. https://doi.org/10.1097/01.icu.0000193074.24746.e6

Ebihara Y, Kato S, Oshika T, Yoshizaki M, Sugita G (2006) Posterior capsule opacification after cataract surgery in patients with diabetes mellitus. J Cataract Refract Surg 32:1184-1187. https://doi.org/10. 1016/j.jcrs.2006.01.100

Findl O, Buehl W, Bauer P, Sycha T (2007) Interventions for preventing posterior capsule opacification. Cochrane Database Syst Rev:1-75. https://doi.org/10.1002/14651858.CD003738.pub2

Fong CSU, Mitchell P, Rochtchina E, Cugati S, Hong T, Wang JJ (2014) Three-year incidence and factors associated with posterior capsule opacification after cataract surgery: the Australian prospective cataract surgery and age-related macular degeneration study. Am J Ophthalmol 157:171-179.e1. doi: https://doi.org/10.1016/j.ajo.2013.08.016

Garrison LP, Neumann PJ, Erickson P, Marshall D, Mullins CD (2007) Using real-world data for coverage and payment decisions: the ISPOR Real-World Data Task Force report. Value Heal 10:326335. https://doi.org/10.1111/j.1524-4733.2007.00186.x

Gauthier L, Lafuma A, Laurendeau C, Berdeaux G (2010) Neodymium: YAG laser rates after bilateral implantation of hydrophobic or hydrophilic multifocal intraocular lenses: twenty-four month retrospective comparative study. J Cataract Refract Surg 36:1195-1200. https://doi.org/10.1016/j.jcrs.2010.01.027

Greenberg PB, Tseng VL, Wu W-C, Liu J, Jiang L, Chen CK, Scott IU, Friedmann PD (2011) Prevalence and predictors of ocular complications associated with cataract surgery in United States veterans. Ophthalmology 118:507-514. https://doi.org/10.1016/j.ophtha.2010. 07.023

Guo S, DiPietro LA (2010) Factors affecting wound healing. J Dent Res 89:219-229. https://doi.org/10.1177/0022034509359125

Hayashi K, Hayashi H, Nakao F, Hayashi F (2002) Posterior capsule opacification after cataract surgery in patients with diabetes mellitus. Am J Ophthalmol 134:10-16

Karahan E, Er D, Kaynak S (2014a) An overview of Nd:YAG laser capsulotomy. Med Hypothesis Discov Innov Ophthalmol 3:45-50

Karahan E, Tuncer I, Zengin MO (2014b) The effect of ND:YAG laser posterior capsulotomy size on refraction, intraocular pressure, and macular thickness. J Ophthalmol 2014:1-5. https://doi.org/10.1155/ 2014/846385

Kato K, Kurosaka D, Bissen-Miyajima H, Negishi K, Hara E, Nagamoto $\mathrm{T}$ (1997) Elschnig pearl formation along the posterior capsulotomy margin after neodymium:YAG capsulotomy. J Cataract Refract Surg 23:1556-1560. https://doi.org/10.1016/S0886-3350(97)80029-6

Kossack N, Schindler C, Häckl D, Weinhold I (2016) Hydrophobes oder hydrophiles Acrylat: Linsenimplantate und Komplikationsrisiken. Monitor Versorgungsforschung 02:58-62

Lara-Smalling A, Cakiner-Egilmez T (2014) Diabetes and cataract surgery: preoperative risk factors and positive nursing interventions. Insight 39:18-20

Li Y, Wang J, Chen Z, Tang X (2013) Effect of hydrophobic acrylic versus hydrophilic acrylic intraocular lens on posterior capsule opacification: meta-analysis. PLoS One. doi: https://doi.org/10. 1371/journal.pone.0077864

Lundström M, Barry P, Henry Y, Rosen P, Stenevi U (2012) Evidencebased guidelines for cataract surgery: guidelines based on data in the European Registry of Quality Outcomes for Cataract and Refractive Surgery database. J Cataract Refract Surg 38:1086-1093. https:// doi.org/10.1016/j.jcrs.2012.03.006
Menapace R (2007) Nachstarbildung nach Intraokularlinsenimplantation. Der Ophthalmol 104:253-264. https://doi.org/10.1007/s00347-0071492-2

Mencucci R, Favuzza E, Boccalini C, Gicquel J-J, Raimondi L (2015) Square-edge intraocular lenses and epithelial lens cell proliferation: implications on posterior capsule opacification in an in vitro model. BMC Ophthalmol 15:5. https://doi.org/10.1186/1471-2415-15-5

Nekolová J, Pozlerová J, Jirásková N, Rozsíval P (2008) Posterior capsule opacification in patients with type 2 diabetes mellitus. Cesk Slov Oftalmol 64:193-196

Nibourg LM, Gelens E, Kuijer R, Hooymans JMM, van Kooten TG, Koopmans SA (2015) Prevention of posterior capsular opacification. Exp Eye Res 136:100-115. https://doi.org/10.1016/j. exer.2015.03.011

Noon A, Hunter RJ, Witte MH, Kriederman B, Bernas M, Rennels M, Percy D, Enerbäck S, Erickson RP (2013) Comparative lymphatic, ocular, and metabolic phenotypes of FOXC2 haploinsufficient and AP2-FOXC2 transgenic mice. Lymphology 39:84-94

Pandey SK, Apple DJ, Werner L, Maloof AJ, Milverton EJ (2004) Posterior capsule opacification: a review of the aetiopathogenesis, experimental and clinical studies and factors for prevention. Indian J Ophthalmol 52:99-112

Pham TQ, Wang JJ, Rochtchina E, Maloof A, Mitchell P (2004) Systemic and ocular comorbidity of cataract surgical patients in a western Sydney public hospital. Clin Experiment Ophthalmol 32:383-387. https://doi.org/10.1111/j.1442-9071.2004.00842.x

Pigeot I, Stat D, Ahrens W, Biol D (2008) Establishment of a pharmacoepidemiological database in Germany: methodological potential, scientific value and practical limitations. 1:215-223. doi: https://doi.org/10.1002/pds

Praveen MR, Vasavada AR, Shah GD, Shah AR, Khamar BM, Dave KH (2014) A prospective evaluation of posterior capsule opacification in eyes with diabetes mellitus: a case-control study. Eye (Lond) 28: 720-727. https://doi.org/10.1038/eye.2014.60

Prokofyeva E, Wegener A, Zrenner E (2013) Cataract prevalence and prevention in Europe: a literature review. Acta Ophthalmol 91: 395-405. https://doi.org/10.1111/j.1755-3768.2012.02444.x

Raj SM, Vasavada AR, Johar SRK, Vasavada VA, Vasavada VA (2007) Post-operative capsular opacification: a review. Int J Biomed Sci 3: 237-250

Schriefl SM, Leydolt C, Stifter E, Menapace R (2015) Posterior capsular opacification and Nd:YAG capsulotomy rates with the iMics Y-60H and Micro AY intra-ocular lenses: 3-year results of a randomized clinical trial. Acta Ophthalmol 93:342-347. https://doi.org/10.1111/aos.12543

Smith AF, Lafuma A, Berdeaux G, Berto P, Brueggenjuergen B, Magaz S, Auffarth GU, Brezin A, Caporossi A, Mendicute J (2005) Costeffectiveness analysis of PMMA, silicone, or acrylic intra-ocular lenses in cataract surgery in four European countries. Ophthalmic Epidemiol 12:343-351. https://doi.org/10.1080/09286580500180598

Sundelin K, Almarzouki N, Soltanpour Y, Petersen A, Zetterberg M (2014) Five-year incidence of Nd:YAG laser capsulotomy and association with in vitro proliferation of lens epithelial cells from individual specimens: a case control study. BMC Ophthalmol 14:116. https://doi.org/10.1186/1471-2415-14-116

Swart E (2014) Health care utilization research using secondary data. In: Health Care Utilization in Germany. Springer, New York, pp 63-86

Vasavada AR, Raj SM, Shah A, Shah G, Vasavada V, Vasavada V (2011) Comparison of posterior capsule opacification with hydrophobic acrylic and hydrophilic acrylic intraocular lenses. J Cataract Refract Surg 37:1050-1059. https://doi.org/10.1016/j.jcrs.2010.12. 060

Wormstone IM, Wang L, Liu CSC (2009) Posterior capsule opacification. Exp Eye Res 88:257-269. https://doi.org/10.1016/j.exer.2008.10. 016 